\title{
Three difficult airway management strategies in the same patient at three different times
}

\author{
Ezgi Erkilic ${ }^{1}$, Handan Gulec ${ }^{2}$, Zafer Yasin Konya ${ }^{1}$, Selvinaz Hocuk ${ }^{2}$, Eda Uysal Aydın ${ }^{1}$, Mehmet \\ Sahap $^{2}$
}

1-Ankara City Hospital. Üniversiteler, Bilkent Blv. No 1, 06800-Çankaya, Ankara, Turkey.

2-Ankara Yildirim Beyazit University, Kızılca Mahallesi, 06760 Çubuk, Ankara, Turkey.

Correspondence: Dr Handan Güleç; E-mail: handandrhandan@yahoo.com.tr; Mobile: +90 5056725948

\begin{abstract}
Unpredictable difficult intubation is a commonly faced clinical issue and one of the most important reasons of morbidity related to anesthesia. We present a case of a $50 \mathrm{y}$ old, $100 \mathrm{~kg}, 1.8 \mathrm{~m}$ tall (BMl=37) male patient, taken to OR (transoral robotic) for a planned biopsy because of a mass in his larynx. Videolaryngoscope was used two times but still intubation was unsuccessful. Fiberoptic bronchoscope (FOB) assisted nasotracheal intubation was chosen to be used. Intubation was unsuccessful even after two attempts by a highly experienced anesthetist. After that, face mask was applied and ventilation started. Then blind oral intubation by the same anesthetist was attempted and it was successful. Ten days later, FOB guided nasal intubation was successful and 7 days later tracheostomy had to be done to secure airway. We stress that even for an apparently an easy airway the anesthetist needs to be ready to face every challenge and execute different strategies one by one when facing difficult airway scenario.
\end{abstract}

Key words: Difficult Airway; Cleft lip; Cleft palate; Malformation, Congenital; Intubation

Citation: Erkilic E, Gulec H, Konya ZY, Hocuk S, Aydın EU, Sahap M. Three difficult airway management strategies in the same patient at three different times. Anaesth. Pain Intensive Care 2020;24(4):450-452.

Received: 7 January 2020, Reviewed: 6 May 2020, Accepted: 7 May 2020

\section{Introduction}

Unpredictable difficult intubation is a commonly faced clinical issue and one of the most important reasons of morbidity related to anesthesia. ${ }^{1,2}$ ASA defines the difficult intubation as; 'longer than $10 \mathrm{~min}$ of trial of inserting the endotracheal tube or more than 3 times of unsuccessful insertion by an experienced anesthesiologist'. ${ }^{3}$ The incidence has been quoted to vary between $1-13 \%$, difficult intubation can occur usually in $2-3 \%$ of the cases. ${ }^{3}$ The incidence of difficult airway varies $1-4 \%$ for the patients with Cormack and Lehane scale 4. Impossible intubation has been noticed in $0.05-0.35 \%$ of cases. ${ }^{2}$ This rate, however, is changed to $0.3-13 \%$ during unpredictable difficult airway and more and tougher clinical issues may have to be encountered in this category of the patients. $^{2,3}$ Different procedures, alone or in combination, can be used when facing a difficult intubation, e.g., intubation with fiberoptic bronchoscope (FOB), blind or nasal intubation, intubating laryngeal mask airway (ILMA). In the last decade, the use of videolaryngoscopes (VL) for endotracheal intubation has become routine in the clinical setting, especially in unexpected difficult airway management. ${ }^{4,5} \mathrm{VL}$ eliminates the need for a direct line of sight between the operator and glottis. The potential benefit of VL in difficult airway management is highlighted in different international guidelines $^{6,7}$ and has been the subject of a Cochrane analysis. ${ }^{8}$

\section{Case report}

A 50-year old, $100 \mathrm{~kg}, 1.8 \mathrm{~m}$ tall (BMI=37) male patient, was taken to OR (transoral robotic) for a planned biopsy because of a mass in his larynx. 
Preoperative airway evaluation was; Mallampati class 2, thyromental space approximately $4 \mathrm{~cm}$ and mouth opening was $3-4 \mathrm{~cm}$. Conventional monitoring according to ASA standards was done and propofol $2.5 \mathrm{mg} / \mathrm{kg}$ and remifentanil $0.5 \mu \mathrm{g} / \mathrm{kg}$ were used for anesthetic induction. Patient was comfortably mask ventilated, so was given rocuronium bromide 0.6 $\mathrm{mg} / \mathrm{kg}$ as a neuromuscular blocking agent. The larynx was watched as grade 4 (Cormack-Lehane) by direct laryngoscopy with Macintosh blade No. 4. Intubation was unsuccessful in two attempts. Then VL was used twice, but still intubation was unsuccessful. FOB guided nasotracheal intubation was decided to be done. Intubation was unsuccessful after two attempts with FOB by a highly experienced anesthetist. After that, face mask was placed and ventilation was resumed. After oxygenation for 4-5 min blind oral intubation was attempted by the same physician and it was successful. No issues occurred during patient's surgery. Sugammadex was used to reverse the relaxant and the patient was awakened. Mild sore throat was the only complaint after the surgery.

After 10 days the same patient was scheduled to be operated again for mass excision with transoral robotic surgery. FOB guided nasotracheal intubation under sedation was planned. Full preparations for tracheostomy were undertaken. FOB was successful at the first attempt. Then the routine anesthesia was administered and the surgery completed.

The patient started bleeding from the lesion area after 7 days, so had to be taken promptly to the OR during the evening hours to control the bleeding. Intubation attempt was unsuccessful lead, do without any further attempts, the ENT specialist was asked to proceed for tracheostomy. The airway was secured and the patient successfully ventilated. Bleeding was secured and the patient shifted to surgical ICU for postoperative care.

\section{Discussion}

Unpredictable airway is one of the most important reasons of mortality and morbidity related to anesthesia. ${ }^{9}$ Three different scenarios can be faced after anesthetic induction: 'failure to ventilate', 'failure to intubate' or 'failure to ventilate, failure to intubate'. ${ }^{2,3}$ Predicting the difficulty of intubation is done by: Mallampati score, Wilson risk, laryngoscopic evaluation, sternomental space, anterior mandibular site anatomy, extension angle of the head, radiologic evaluation and CT. In our patient, we came across with unexpected difficult intubation because of the lack of adjustment to these difficult intubation criteria.

Difficult intubation and difficult mas' ventilation can be caused by; anatomical reasons of the patient (short and muscled neck, limited neck movements and limited mouth opening etc.), congenital abnormalities (choanal atresia, cleft lip and palate) inflammatory, degenerative fibrotic conditions (abscess, epiglottitis etc.), tumors, endocrine reasons, foreign material. Our patient had no signs of difficult airway except he had a BMI as 37, mallampati class 2, tyhromental space was approximately $4 \mathrm{~cm}$ and mouth opening was 3-4 $\mathrm{cm}$.

According to the guidelines published by Difficult Airway Society (DAS), one needs to have a back-up plans B, C or D. Normal intubation plan, second intubation plan as plan B using (LMA, VL, FOB), sustaining the oxygenation and ventilation of the patient and if the previous plans failed, awakening the patient and postponing the surgery as plan $\mathrm{C}$, and plan $\mathrm{D}$ is the salvage of the patients in 'cannot ventilate, cannot intubate' situation by surgical cricothyroidotomy.

In our patient, plan A was unsuccessful so we proceeded to plan $\mathrm{B}$, as $\mathrm{VL}$ has the potential to enhance the glottic view in patients with difficult airway management. Previous studies showed faster visualization ${ }^{10}$ and better visibility of the glottis structures when using indirect laryngoscopy in a normal and simulated difficult airway. ${ }^{11,12}$ But we failed again and we wanted to awake the patient since mask ventilation was good but lastly blind intubation was executed. Unpredicted difficult intubation and multiple attempts probably caused some laryngeal edema, and it may explain why our FOB was unsuccessful, which is considered to be safe and effective in patients with both anticipated and unanticipated difficult airways. ${ }^{13,14}$

We made preparations for predicted difficult airway and executed a successful intubation with FOB under sedation at our second operation.

Our patient's sudden operation caused by bleeding had unsuccessful A-B-C plans and tracheostomy was done. 
We think the use of 3 different difficult airway algorithms at different times on the same patient is significant.

As a consequence, even unpredicted, difficult airway requires the anesthetists to be ready to face this challenge and execute different strategies one by one when facing. Anesthetist needs to stay cool and do the most convenient airway management alternative according to the situation and his/her experience to prevent the hypoxic lesions. On the other hand, it must be kept in mind that remaining methods to manage the difficult airway may not always have successful results.

\section{Conflict of interest}

None declared by the authors.

\section{Authors' contribution}

All authors took part in the case management, manuscript preparation, editing and literature search.

\section{References}

1. Combes X, Le Roux B, Suen P, Dumerat M, Motamed C, Sauvat $S$, et al. Unanticipated difficult airway in anesthetized patients. Anesthesiology. 2004;100:1146- 1150. [PubMed] DOI: $\underline{10.1097 / 00000542-200405000-00016}$

2. Petrini F, Accorsi A, Adrario E, Agrò F, Amicucci G, Antonelli $M$, et al. Recommendations for airway control and difficult airway management. Minerva Anesthesiol. 2005;71:617657. [PubMed]

3. Janssens M, Hartstein G. Management of difficult intubation. Eur J Anaesthesiol. 2001;18:3-12. [PubMed] DOI: 10.1046/j.0265-0215.2000.00777.x

4. Aziz M. Use of video-assisted intubation devices in the management of patients with trauma. Anesthesiol Clin. 2013;31(1):157-166. [PubMed] DOI: 10.1016/j.anclin.2012.10.001

5. Paolini JB, Donati F, Drolet P. Review article: videolaryngoscopy: another tool for difficult intubation or a new paradigm in airway management? Can J Anesth. 2013;60(2):184-191. [PubMed] DOI: 10.1007/s12630-012-9859-5

6. Frerk C, Mitchell VS, McNarry AF, Mendonca C, Bhagrath R, Patel A, et al. Difficult Airway Society 2015 guidelines for management of unanticipated difficult intubation in adults. Brit J Anaesth. 2015;115(6):827-848. [PubMed] DOI: $10.1093 /$ bja/aev371
7. Piepho T, Cavus E, Noppens R, Byhahn C, Dörges V, Zwissler $\mathrm{B}$, et al. $\mathrm{S} 1$ guidelines on airway management. Anaesthesist. 2015 Nov;64(11):859-873. [PubMed] DOI: 10.1007/s00101-015-0087-6

8. Lewis SR, Butler AR, Parker J, Cook TM, Smith AF. Videolaryngoscopy versus direct laryngoscopy for adult patients requiring tracheal intubation. Cochrane Database Syst Rev. 2016 Nov 15;11(11):CD011136. [PubMed] DOI: 10.1002/14651858.CD011136.pub2

9. Combes X, Le Roux B, Suen P, Dumerat M, Motamed C, Sauvat $S$, et al. Unanticipated difficult airway in anesthetized patients: prospective validation of a management algorithm. Anesthesiology. 2004 May;100(5):1146-1150. [PubMed] DOI: $10.1097 / 00000542-200405000-00016$

10. Rosenstock CV, Thøgersen B, Afshari A, Christensen AL, Eriksen C, Gätke MR. Awake fiberoptic or awake video laryngoscopic tracheal intubation in patients with anticipated difficult airway management: a randomized clinical trial. Anesthesiology. 2012 Jun;116(6):1210-1216. [PubMed] DOI: $10.1097 / A L N .0 b 013 e 318254 d 085$

11. Byhahn C, Iber T, Zacharowski K, Weber CF, Ruesseler M, Schalk $\mathrm{R}$, et al. Tracheal intubation using the mobile C-MAC video laryngoscope or direct laryngoscopy for patients with a simulated difficult airway. Minerva Anestesiol. 2010 Aug;76(8):577-583. [PubMed]

12. Sakles JC, Mosier J, Chiu S, Cosentino M, Kalin L. A comparison of the C-MAC video laryngoscope to the Macintosh direct laryngoscope for intubation in the emergency department. Ann Emerg Med. 2012 Dec;60(6):739-748. [PubMed] DOI: 10.1016/j.annemergmed.2012.03.031

13. Collins SR, Blank RS. Fiberoptic intubation: an overview and update. Respir Care. 2014;59:865-878. [PubMed] DOI: 10.4187/respcare.03012

14. Tawfeek MM, Abdelbaky AM. Is fiberoptic bronchoscope a good intubating choice in anesthetized patients with anticipated difficult intubation? Egypt J Anaesth. 2011;27:157-161. DOI: 10.1016/j.egja.2011.06.001 